AperTO - Archivio Istituzionale Open Access dell'Università di Torino

Increased frequency of chromosomal aberrations and sister chromatid exchanges in peripheral lymphocytes of radiology technicians chronically exposed to low levels of ionizing radiations

This is a pre print version of the following article:

Original Citation:

Availability:

This version is available http://hdl.handle.net/2318/144961

since 2016-03-11T09:39:44Z

Published version:

DOI:10.1016/j.etap.2013.12.009

Terms of use:

Open Access

Anyone can freely access the full text of works made available as "Open Access". Works made available under a Creative Commons license can be used according to the terms and conditions of said license. Use of all other works requires consent of the right holder (author or publisher) if not exempted from copyright protection by the applicable law. 


\section{(6) \\ UNIVERSITÀ DEGLI STUDI DI TORINO}

This is an author version of the contribution published on:

Questa è la versione dell'autore dell'opera:

Environmental Toxicology and Pharmacology, 37, 2014

doi:10.1016/j.etap.2013.12.009

The definitive version is available at:

La versione definitiva è disponibile alla URL:

http://dx.doi.org/10.1016/i.etap.2013.12.009 


\title{
Increased frequency of chromosomal aberrations and sister chromatid exchanges in peripheral lymphocytes of radiology technicians chronically exposed to low levels of ionizing radiations.
}

\author{
Alfredo Santovito, Piero Cervella, Massimiliano Delpero \\ University of Turin, Department of Life Sciences and Systems Biology, Via Accademia Albertina $n$. \\ 13, 10123 Torino, Italy
}

\begin{abstract}
Chromosome aberrations (CAs) and sister chromatid exchanges (SCEs) frequencies were estimated in peripheral lymphocytes from 21 radiology technicians, and from 21 nonexposed control subjects. We exclusively considered individuals who neither smoke nor consume drugs or alcohol for a period of at least two years prior to the analysis. Significant differences were found between exposed and controls in terms of SCEs and CAs frequencies.

Technicians showed a significant higher number of high-frequency individuals (HFIs) with respect to the control group. Nevertheless, the mean frequency of SCEs observed among technician HFIs did not significantly differ with respect to that observed among control HFIs. Vice versa, the nonHFIs belonging to technicians group showed a statistically higher difference in the SCEs/NSM value with respect to the non-HFIs belonging to control group. Since the differences in the SCEs frequencies between the two groups are due to non-HFIs, our results seem to indicate a general genotoxic effect of the IR, not affected by HFIs. Among technicians, the level of chromosome damage correlated neither with years of

radiation exposure nor with the age of the subjects. Vice versa, in the control group, a positive correlation was found between the number of SCEs and age. In both samples the gender status did not influence the frequencies of CAs and SCEs.

Our results suggest that chronic long-term exposure to low doses of ionizing radiation could increase the CAs and SCEs frequencies. This study reinforces the relevance of the biomonitoring of hospital workers chronically exposed to ionizing radiation.
\end{abstract}

\section{Introduction}

Personnel employed in radiology units represent workers chronically exposed to low doses of ionizing radiation (IR). The International Commission on Radiological Protection (ICRP) recommends an effective dose limit of $20 \mathrm{mSv}$ per year, averaged over 5 years, with the further provision that the effective dose should not exceed $50 \mathrm{mSv}$ in any single year (ICRP, 2001). Although in many hospital radiology units the radiation exposure remains below these levels, there is a higher risk for hospital workers handling diagnostic X-ray machines and $\gamma$-cameras due to the chronic but cumulative exposure to low doses of IR.

One consequence of the exposure to IR is the formation of free radicals, such as peroxynitrites and hydroxyl radicals (Zhang et al., 2000; Spitz et al., 2004), able to produce some important alterations in the living cells. At DNA level, IR exerts its genotoxic effect by the induction of singleand double-strand breaks, a-basic sites and oxidized bases. Moreover, the exposure to IR has been associated with gene mutations, amplification of genetic material, chromosomal rearrangements and increased frequencies of apoptosis, chromosomal aberrations (CAs), micronuclei and sister chromatid exchanges (SCEs) (Lazutka et al., 1999; Limoli et al., 2000; Engin et al., 2005; Dias et al., 2007; Sari-Minodier et al., 2007; Sakly et al., 2012a,b). These genotoxic effects of the radiations would result in each individual in the induction of a carcinogenic process (Breimer, 1988; Overbeek et al., 1999). 
Monitoring of personnel occupationally exposed to IR consists of regular film dosimetric control. Nevertheless, this physical control makes it difficult to calculate the effective doses and to determine which are the risks of whole-body radiation exposure. Moreover, personal dosimeter may underestimate the real exposure, not only because of the detection threshold of dosimeters but also because of improper wearing (Zakeri and Hirobe, 2010). In this scenario, the additional information obtained with cytogenetic studies, complement physical dosimetry data and enables better evaluation of the radiation health effects.

It is known that cancer incidence among healthy individuals of a population increases with increased levels of CAs in their circulating lymphocytes (Bonassi et al., 2000, 2004). Because an increased frequency of CAs was found to be a sensitive indicator of exposure to IR (Carrano and Natarajan, 1988), the CAs assay has been applied to monitor workers professionally exposed to low but cumulative levels of IR (Lazutka et al., 1999; Zakeri and Hirobe, 2010; Bonassi et al., 1997; Maffei et al., 2004; Ballardin et al., 2007).

Analogously to CAs assay, the SCEs analysis is widely used to assess the genomic damage, because it represents a sensitive method for identifying physical DNA-damaging agents that directly induce DNA strand breaks (Natarajan and Mullenders, 1987).

The objective of the present investigation was to evaluate the frequencies of CAs and SCEs in a sample of hospital radiology technicians chronically exposed to low doses of IR, in comparison with matched control individuals. Radiology technicians were chosen as study group because they represent one of the most IR exposed hospital workers categories. Indeed, although over the recent decades the exposures of workers in conventional radiology are generally well controlled as a result of efficient protection policy among radiologists, radiology technicians and interventional physicians, such as cardiologists, are the worker categories that receive some of the highest radiation doses in the medical sector (UNSCEAR, 2008; Ballardin et al., 2007; National Research Council BEIR V, 1990).

Effects of donor age, gender and years of exposure on CAs and SCEs frequencies were also evaluated. Finally, because cigarette smoking was found to affect both the radiosensitivity of the cells (Wang et al., 2000) and the fidelity of DNA repair systems (Au et al., 1998), in our study we recruited only non-smokers subjects.

\section{Materials and methods}

\subsection{Study population}

The exposed group comprised 21 technicians (13 males and 8 females) working in a hospital radiology unit and chronically exposed to low doses of IR ("20 mSv/year, as established by the Italian law). Their occupational exposure to X-rays ranged from 1 to 29 years (mean \pm S.D., $9.714 \pm$ 8.730). The control group consisted of 21 unexposed healthy individuals (13 males and 8 females) belonging to the administrative staff, and working in the same hospital without any work-related exposure to hazardous agents and with no history of radiation exposure. All the subjects of both groups lived in the same urban area. The procedures followed in this work were approved by the local responsible committee on human experimentation and have been performed in accordance with the ethical standards laid down in the 1964 Declaration of Helsinki. All the participants were healthy volunteers that received information about the study and that gave their written consent. Prior to blood collection, each individual was extensively interviewed by a specialized physician who filled in a structured questionnaire specifying gender, date of birth, smoking status, dietary habits, alcohol consumption, workrelated exposure to hazardous agents, previous exposure to diagnostic X-ray as a patient, and use of therapeutic drugs. In our sample we exclusively considered individuals who neither smoke nor consume drugs or alcohol, and who were not exposed to X-ray for medical treatments, for a period of at least two years prior to the analysis. We do not have quantitative data about the exact radiation doses received by the workers. Nevertheless, when interviewed, technicians confirmed that their activity conforms to the radiation protection 
procedures as established by the Italian law, and that their exposure to IR was below the permitted levels ( $<20 \mathrm{mSv}$ per year). In this sense, results of this study must be considered as the effect of their prolonged exposition to low levels of IR during their work activity.

\subsection{Blood sample collection}

Blood samples were obtained by venipuncture $(5-10 \mathrm{~mL})$ and collected into heparinised tubes, for genotoxicity testing. All blood samples were coded, cooled (4 \#C), and processed within $2 \mathrm{~h}$ after collection. Heparinized venous blood $(0.3 \mathrm{~mL})$ was cultured in $25 \mathrm{~cm} 2$ flasks in $6 \mathrm{~mL}$ RPMI-1640 (Biological Industries) supplemented with 20\% fetal calf serum (FCS), 2\% of the mitogenic agent phytohemagglutinin-M (PHA, Difco, $0.2 \mathrm{~mL})$, L-glutamine $(2 \mathrm{mM})$, antibiotics (100 IU/mL penicillin, and $100 \mu \mathrm{g} / \mathrm{mL}$ streptomycin). The cultures were incubated for $48 \mathrm{~h}$ for CAs assay and $72 \mathrm{~h}$ for SCEs assay, at $37{ }^{\circ} \mathrm{C}$ in an atmosphere of $5 \% \mathrm{CO}_{2}$ in the air. To arrest cells in mitosis, colchicine (Sigma, $0.25 \mu \mathrm{g} / \mathrm{mL}$ ) was added at a concentration of $0.06 \mu \mathrm{g} / \mathrm{mL}$ during the last $2 \mathrm{~h}$ of culture. Chromosome preparation was done following standard procedures.

Cells were centrifuged $(\approx 800 \mathrm{rpm}$ for $5-10 \mathrm{~min})$, slowly resuspended in $10 \mathrm{~mL}$ of pre-warmed hypotonic solution $\left(0.075 \mathrm{M} \mathrm{KCl}\right.$, prewarmed to $\left.37^{\circ} \mathrm{C}\right)$, and incubated for 15 min in a $37^{\circ} \mathrm{C}$ water bath. The cells were centrifuged again and fixed in cold methanol:acetic acid (3:1) for 20 min at room temperature. The treatment with the fixative was repeated three times. Finally the supernatant was discarded and the pellet, dissolved in a minimal volume of fixative, was seeded on the slides.

\subsection{SCE assay}

To measure SCEs in second division metaphases, bromodeoxyuridine (BrdUrd, 10 "g/mL) was added at $24 \mathrm{~h}$. BrdUrd closely resembles thymidine and is efficiently incorporated into the elongating DNA strands during replication. After two cell cycles in BrdUrd medium, the two sister chromatids differ in the amount of BrdUrd present and the chromatid with more BrdUrd is lighter in appearance ("bleaching" effect). For sister chromatid differentiation, the cells were stained with fluorescence dye Hoechst 33258 (Sigma, 10 "g/mL, $20 \mathrm{~min}$, at room temperature in the dark) and subsequently irradiated with an 8-W UV lamp $(254 \mathrm{~nm})$ at a distance of about $20 \mathrm{~cm}$ for $30 \mathrm{~min}$. Subsequently, slides were incubated in $2 \times$ SSC (standard saline concentration) for $1 \mathrm{~h}$ at 60 \#C and then stained with 5\% Giemsa (Sigma) in Sörensen buffer for 10 min.

Microscopic analyses were performed at 1000x magnification on a light microscope (CX40, Olympus, Tokyo, Japan). In order to determine the number of SCE/cell for each subject we scored 50 well-spread second-division metaphases containing 46 chromosomes. A total of 100 cells from each donor were scored for the determination of the replication index (RI), calculated according to the following formula: $\mathrm{RI}=(M 1+2 M 2+3 M 3) / N$, where $M 1, M 2$ and $M 3$ represent the number of cells undergoing first second and third mitosis and $N$ is the total number of scored metaphase (NSM).

\subsection{CAs assay}

Air-dried slides were stained for 20 min with 5\% Giemsa stain ( $\mathrm{pH}$ 6.8) prepared in a Sörensen buffer. For each subject, a total of 200 well-spread metaphases were analyzed for the following categories of CAs: chromatid breaks $(B \%)$, chromosome breaks $(B \% \%)$, dicentrics (Dic), acentric fragments (AF), and Tri- or Tetra-radials (TR). Gaps (a-chromatid lesions) were not scored as CAs. Cells containing any type of chromosomal aberrations were scored as cells with aberrations (CAB).

\subsection{Statistical analysis}

Statistical analysis was assessed using the SYSTAT software statistical package programme (version 10.0, Inc., Chicago, IL, USA). The Student's $t$-test was used to evaluate statistical differences between groups in terms of mean age and years of employment. Non-parametric Wilcoxon test was used to compare the mean frequencies of SCEs and CAs between exposed workers and controls and between sexes. Multiple regression analysis was used to evaluate the influence of age and years of employment on SCEs and CAs frequencies of both groups. The threshold value to define high-frequency cells (HFCs) was calculated according to Carrano and Moore (1982). It was based on the 95th percentile of the pooled distribution of the number of SCEs per cell in the control population. For each subject, the expected number of HFCs was calculated 
according to Bonassi et al. (1999). The numbers of HFCs and HFIs for groups were compared using the chi-square test. All $P$-values were two tailed and the level of statistical significance was set at $P$ $<0.05$ for all tests.

\section{Results}

\subsection{Characteristic of the samples}

Demographic characteristics of control and exposed workers are reported in Table 1. No significant differences were found between groups in terms of mean age $(P=0.140)$, sex $(P=1)$ and years of employment $(P=0.445)$. Similarly, in both groups, no significant differences were found between sexes in terms of mean age ( $P=0.779$ and $P=0.291$ for exposed and control subjects, respectively) and years of employment $(P=0.528$ and $P=0.573$ for exposed and control subjects, respectively).

\subsection{Sister chromatid exchanges analysis}

Results of SCEs analyses are summarized in Table 2. Significant differences were found between technicians and controls in terms of SCEs/NSM $(P=0.003)$ and RI value $(P=0.001)$. In both groups, no significant differences were found between sexes in terms of SCEs frequency $(P=0.674$ and $P=0.401$ for exposed and control subjects, respectively) and RI value $(P=0.327$ and $P=$ 0.484 for exposed and control subjects, respectively). Among technicians, regression analysis indicated that the age and the exposure years did not influence the frequency of SCEs $(P=0.993$ and $P=0.801$, respectively). Vice versa, in the control group, a positive correlation was found between SCEs/NMS and age $(P=0.017)$ (Table 5).

Cells with 10 or more SCEs were defined as HFCs according to Carrano and Moore (1982). Individuals for whom more than five cells were detected that contained more than 10 SCEs were classified as HFIs. In the total sample 14 subjects were identified as HFIs (11 among technicians and 3 among controls) (Table 3). Our results indicated that technicians showed a significant highly number of HFIs $(P=0.010)$ and HFCs $(P<0.001)$ with respect to controls. Nevertheless, the frequency of SCEs observed among technician HFIs did not significantly differ with respect to that observed among control HFIs $(P=0.109)$. Vice versa, non-HFI individuals belonging to the technicians group showed a statistically $(P=0.013)$ higher SCEs/NSM value with respect to nonHFI individuals belonging to control group (Table 3 ).

\subsection{Chromosomal aberrations analysis}

Results of CA analyses are presented in Table 4. Significant differences were found between technicians and controls in terms of CAs/NSM $(P=0.006)$ and CAB/NSM $(P=0.004)$. Vice versa, in both groups, no significant differences were found between genders in terms of chromosomal damage $(P=0.235$ and $P=0.832$ for exposed and control groups, respectively). Finally, among exposed, the frequency of CAs did not correlate either with years of radiation exposure $(P=0.920)$ or with age $(P=0.887)$. Similarly, in the control group, no significant correlation was found between years of employment $(P=0.611)$, age $(P=0.285)$ and the frequency of CAs (Table 5$)$.

\section{Discussion}

In order to evaluate the level of the potential genomic damage due to the chronic exposure to low levels of IRs, we performed cytogenetic analyses by using CAs and SCEs assays on peripheral lymphocytes of hospital radiology technicians. Results of our study showed significant difference in the CAs $(P=0.006)$ and $\mathrm{CAB}(P=0.004)$ frequencies between technicians and control group. This observation is in line with previous published data reporting a significantly higher frequency of CAs among workers chronically exposed to IR (Sakly et al., 2012a,b; Zakeri and Hirobe, 2010; Maffei et al., 2004; Ballardin et al., 2007; Cardoso et al., 2001; Zakeri and Assaei, 2004; Güerci et al., 2006). As expected, the number of chromatid breaks was higher than that of chromosome breaks. Indeed, since the production of a chromosome break requires two independent breaks, low doses of IR may 
increase the number of chromatid breaks more easily than that of chromosome breaks. Moreover, the absence of rings, mostly induced by high radiation doses, was considered by different authors the demonstration of the low levels of IR experienced by the workers (Balasem et al., 1992; Barquinero et al., 1993). Interestingly, we found 4 dicentrics among control subjects and 2 among technicians (Table 4).

It could be hypothesized that the higher number of dicentrics found in the control group was the result of an unknown exposure of these subjects to environmental xenobiotics and/or of a higher capacity of the technicians, chronically exposed to low doses of IR, to induce apoptosis in cells carrying severe chromosomal damages as a mechanism of individual adaptive response (Shadley and Wolff, 1987; Vijayalaxmi et al., 1995; Ikushima et al., 1996).

The frequency of CAs serves as the most reliable biological exposure marker in case of acute accidental radiation. Radiology technicians are occupationally exposed to low levels of IR for a long time. Hence, they can suffer from various adverse effects of radiations as a result of their long professional life (Tug et al., 2013). For this reason the combination of CAs test with other tests, such as SCEs and micronuclei assays, could better quantify the genomic damages in subjects professionally exposed to physical and chemical agents.

SCEs are S-phase associated repair processes that result in symmetrical exchanges between newly replicated chromatids and their sisters. Although the SCEs are seen in most normal human cells, in cultured mammalian cells changes in their frequency have been considered as general indices of genomic damage (Natarajan and Mullenders, 1987). Studies about the influence of the radiation on the frequency of SCEs are discordant. Indeed, some published studies evidenced a not significant increase of SCEs rate among radiation-exposed individuals (Gundy et al., 1984; Sahin et al., 1995; Sonmez et al., 1997; Maes et al., 2006). Erol et al. (2002) observed that the ionizing radiation dose to which invasive cardiology workers were exposed did not induce an increase in the frequency of SCEs, but could induce an increase of chromosomal aberrations. Vice versa, in agreement with other previous findings (Tug et al., 2013; Engin et al., 2005; Bozkurt et al., 2003; Cardoso et al., 2001; Ray et al., 2001), our study reveals a significantly increased frequency of SCEs among radiation-exposed individuals compared to controls. A possible explanation could be that one of the consequences of the exposure to IR is the production of free radicals able to induce higher levels of SCEs (Ray et al., 2001). Nevertheless, it should be emphasized that the DNA damage measured in an exposed individual is the result of the equilibrium between inflicted damage and its repair. In this scenario, increased levels of SCEs could represent an important signal, because SCEs are considered to be the consequence of DNA-replication errors on a damaged template. Thus, the SCEs assay could have important applications in those cases in which a defect in DNA repair is suspected (Garcia-Sagredo, 2008).

It was suggested that cells with a high frequency of SCEs represent a long-living subset of lymphocytes that accumulated SCE-inducing lesions over time. Therefore, the evaluation of HFCs and HFIs seems to be a useful tool for assessing the effect of chronic exposure to genotoxic agents (Bozkurt et al., 2003). In our sample, the technician group showed a significant higher number of HFIs with respect to the control group. Nevertheless, the mean frequency of SCEs observed among technician HFIs did not significantly differ with respect to that observed among control HFIs. Vice versa, the non-HFIs belonging to technicians group showed a statistically higher difference in the SCEs/NSM value with respect to the non-HFIs belonging to control group (Table 3). Since the differences in the SCEs frequencies between the two groups are due to non-HFIs, our results seem to indicate a general genotoxic effect of the IR, not affected by HFIs.

In our study we did not find a relationship between chromosome damage and duration of the exposure, which could be explained by the fact that, during chronic exposure, part of the chromosomal damage can be eliminated in vivo by the death of lymphocytes. Moreover, as postulated by other authors (Sakly et al., 2012a; Mayer et al., 2002), it is possible that the DNA damage induced in vivo in circulating lymphocytes may largely be repaired, thus escaping from 
fixation. As observed by other authors (Zakeri and Assaei, 2004), also in our study the levels of CAs and SCEs did not seem to be influenced by the gender.

Finally, among controls we found a positive correlation between SCEs frequency, but not CAs frequency, and age of the subjects. This finding is in agreement with previously reported data on the age-related incidence of chromosomal damage among control populations. Indeed, while some authors did not find a significant increase of CAs frequency with age (Anderson et al., 1993; Ka suba et al., 1995), others reported a significant correlation between age and SCEs in peripheral blood lymphocytes (Bolognesi et al., 1997; Bender et al., 1998; Stephan and Pressl, 1999). The lack of a similar pattern among technicians could be due to an increased incidence of the chromosomal damage induced by professional exposure among younger individuals. In this scenario the effect of IR could obscure this relationship in the exposed group.

\section{Conclusions}

In conclusion, this work evidence that a chronic long-term exposure to low doses of IR, even below permitted levels, could result in increased CAs and SCEs frequencies. These data reinforce the relevance of biomonitoring procedures of the hospital workers chronically exposed to IR.

\section{Acknowledgements}

We are grateful to all volunteers who participated in this study. This work was supported by grants from the Italian Ministry of University and Scientific Research (ex 60\%).

Appendix A. Supplementary data

Supplementary data associated with this article can be found, in the online version, at http://dx.doi.org/10.1016/j.etap. 2013.12.009.

\section{References}

Anderson, D., Francis, A.J., Godbert, P., Jenkinson, P.C., Butterworth, K.R., 1993. Variability in chromosome aberrations, sister chromatid exchanges, and mitogen-induced blastogenesis in peripheral lymphocytes from control individuals. Env. Health. Persp. 101 (3), 83-88.

Au, W.W., Cajas-Salazar, N., Salama, S., 1998. Factors contributing to discrepancies in population monitoring studies. Mutat. Res. 400, 467-478.

Balasem, A.N., Ali, A.S.K., Mosa, H.S., Hussian, K.O., 1992. Chromosomal aberration analysis in peripheral lymphocytes of radiation workers. Mutat. Res. 271, 209-211.

Ballardin, M., Antonelli, A., Cipollini, M., Fallahi, P., Scarpato, R., Tomei, A., Traino, C., Barale, R., 2007. Induction of chromatid-type aberrations in peripheral lymphocytes of hospital workers exposed to very low doses of radiation. Mutat. Res. - Genet. Toxicol. Env. Mutag. 626 (1-2), 61-68.

Barquinero, J.F., Barrios, L., Caballin, M.R., Miro, R., Ribas, M., Subias, A., Egozcue, J., 1993. Cytogenetic analysis of lymphocytes from hospital workers occupationally exposed to low level of ionizing radiation. Mutat. Res. 286, 275-279.

National Research Council, 1990. Committee on the biological effects of ionizing radiation. 1990. Health Effect of exposure to low levels of ionizing radiation, BEIR V. National Academy Press http://www.nap.edu/openbook.php?record id=1224\&page=R1

Bender, M.A., Preston, R.J., Leonard, R.C., Pyatt, B.E., Gooch, P.C., Shelbey, M.D., 1998. Chromosomal aberration and sister-chromatid exchanges frequencies in peripheral blood lymphocytes of a large human population sample. Mutat. Res. 294, 421-433.

Bolognesi, C., Abbondandolo, A., Barale, R., Canalone, R., Dalpra, L., De Ferrari, M., Degrassi, F., Forni, A., Lamberti, L., Bonassi, S., 1997. Age-related increase of sister-chromatid exchanges, 
chromosome aberrations, and micronuclei in human lymphocytes. Cancer Epidem. Biom. Prev. 4, 249-256.

Bonassi, S., Forni, A., Bigatti, P., Canevarollo, N., De Ferrari, M., Lando, C., Padovani, P., Bevegni, M., Stella, M., Vecchio, D., Puntoni, R., 1997. Chromosome aberrations in hospital workers: evidence from surveillance studies in Italy (1963-1993). Am. J. Ind. Med. 31, 353-360.

Bonassi, S., Fontana, V., Ceppi, M., Barale, R., Ruggeri, A., 1999. Analysis of correlated data in human biomonitoring studies. The case of high sister chromatid exchange frequency cells. Mutat. Res. 438, 13-21.

Bonassi, S., Hagmar, L., Strömberg, U., Montagud, A.H., Tinnerberg, H., Forni, A., Heikkiliä, P., Wanders, S., Wilhardt, P., Norppa, H., 2000. Chromosomal aberrations in lymphocytes predict human cancer indipendently of exposure to carcinogens. European study group on cytogenetic biomarkers and health. Cancer Res. 60, 1619-1625.

Bonassi, S., Znaor, A., Norppa, H., Hagmar, L., 2004. Chromosomal aberrations and risk of cancer in humans: an epidemiologic perspective. Cytogenet. Genome Res. 104, 376-382.

Bozkurt, G., Yuksel, M., Karabogaz, G., Sut, N., Sovran, F.O., Palanduz, S., Yigitbasi, O.N., Algunes, C., 2003. Sister chromatid exchanges in lymphocytes of nuclear medicine physicians. Mutat. Res. 535, 205-213.

Breimer, L.H., 1988. Ionizing radiation-induced mutagenesis. British J. Cancer 57, 6-18. Cardoso, R.S., Takahashi-Hyodo, S., Peitl, P., Ghilardi-Neto, T., Sakamoto-Hojo, E.T., 2001. Evaluation of chromosomal aberrations, micronuclei, and sister chromatid exchanges in hospital workers chronically exposed to ionizing radiation. Terat. Carcin. Mutag. 21, 431-439.

Carrano, A.V., Natarajan, A.T., 1988. International Commission for Protection Against Environmental Mutagens and Carcinogens, ICPEMC publication no. 14. Considerations for population monitoring using cytogenetic techniques. Mutat. Res. 204, 379-406.

Carrano, A.V., Moore, D.H., 1982. The rationale and methodology for quantifying sister chromatid exchange in humans. In: Heddle, J.A. (Ed.), Mutagenicity: New Horizons in Genetic Toxicology. Academic Press, New York, pp. 267-304.

Dias, F.L., Antunes, L.M.G., Rezende, P.A., Carvalho, F.E.S., Silva, C.M.D., Matheus, J.M., Oliveira Jr., J.V., Lopes, G.P., Pereira, G.A., Balarin, M.A.S., 2007. Cytogenetic analysis in lymphocytes from workers occupationally exposed to low levels of ionizing radiation. Environ. Toxicol. Pharmacol. 23, 228-233.

Engin, A.B., Ergun, M.A., Yurtcu, E., Kan, D., Sahin, G., 2005. Effect of ionizing radiation on the pteridine metabolic pathway and evaluation of its cytotoxicity in exposed hospital staff. Mutat. Res. - Genet. Toxicol. Environ. Mutag. 585 (1-2), 184-192.

Erol, M.K., Oztas, S., Bozkurt, E., Karakelleoglu, S., 2002. Sister chromatid exchange analysis and chromosoma aberration studies in interventional cardiology laboratory workers: one war follow up study. Jpn. Heart J. 43 (2), 159-166.

Garcia-Sagredo, J.M., 2008. Fifty years of cytogenetics: a parallel view of the evolution of cytogenetics and genotoxicology. Biochim. Biophys. Acta 779 (6-7), 363-375.

Güerci, A.M., Grillo, C.A., Dulout, F.N., Seoane, A.I., 2006. Assessment of genotoxic damage in lymphocytes of hospital workers exposed to ionizing radiation in Argentina. Arch. Environ. Occup. Health 61 (4), 163-169.

Gundy, S., Varga, L., Bender, M.A., 1984. Sister chromatid exchange frequency in human lymphocytes exposed to ionizing radiation in vivo and in vitro. Radiat. Res. 100, 47-54.

Kaŝuba, V., Ŝentija, K., Garaj-Vrhovac, V., Fuĉić, A., 1995. Chromosome aberrations in peripheral blood lymphocytes from control individuals. Mutat. Res. 346, 187-193.

ICRP, International Commission on Radiological Protection, 2001. Radiation and Your Patient: A Guide for Medical Practitioners. A Web Module Produced by Committee 3 of the ICRP. Pergamon Press, Oxford, UK.

Ikushima, T., Aritomi, H., Morisita, J., 1996. Radioadaptive response: efficient repair of radiationinduced DNA damage in adapted cells. Mutat. Res. 358, 193-198. 
Lazutka, J.R., Lekevicius, R., Dedonyte, V., Maciuleviciute-Gervers, L., Mierauskiene, J., Rudaitiene, S., Slapsyte, G., 1999. Chromosomal aberrations and sister chromatids exchanges in Lithuanian populations: effects of occupational and environmental exposures. Mutat. Res. 445, 225-239.

Limoli, C.L., Ponnaiya, B., Corcoran, J.J., Giedzinski, E., Kaplan, M.I., Hartmann, A., Morgan, W.F., 2000. Genomic instability induced by high and low LET ionizing radiation. Ad Space Res. 25, 2107-2117.

Maes, A., Van Gorp, U., Verschaeve, L., 2006. Cytogenetic investigation of subjects professionally exposed to radiofrequency radiation. Mutagenesis 21 (2), 139-142.

Maffei, F., Angelini, S., Cantelli Forti, G., Violante, F.S., Lodi, V., Mattioli, S., Hrelia, P., 2004. Spectrum of chromosomal aberrations in peripheral lymphocytes of hospital workers occupationally exposed to low doses of ionizing radiation. Mutat. Res. 547 (1-2), 91-99.

Mayer, C., Popanda, O., Zelezny, O., von Brevern, M.C., Bach, A., Bartsch, H., Schmetzer, P., 2002. DNA repair capacity after g-irradiation and expression profiles of DNA repair genes in resting and proliferating human peripheral blood lymphocytes. DNA Repair 1, 237-250.

Natarajan, A.T., Mullenders, L.H.F., 1987. Sister chromatid exchanges. In: Obe, G., Basler, A. (Eds.), Genetics: basic and applied aspects. Springer-Verlag, Berlin-Heidelberg.

Overbeek, F.J., Pauwels, E.K., Bloem, J.L., Camps, J.A., Geleijns, J., Broerse, J.J., 1999. Somatic effects in nuclear medicine and radiology. Appl. Radiat. Isot. 50, 63-72.

Ray, G.N., Shahid, M., Husain, S.A., 2001. Effect of nitric oxide and malondialdehyde on sister chromatid exchanges in breast cancer. Br. J. Biomed. Sci. 58, 169-176.

Sahin, F.I., Donmez, H., Menevse, S., 1995. Sister chromatid exchanges in radiodiagnostic unit technicians. Hamdard Med. 4, 45-49.

Sakly, A., Gaspar, J.F., Kerkemi, E., Silva, S., Teixeira, J.P., Chaari, N., Cheikh, H.B., 2012a. Genotoxic damage in hospital workers exposed to ionizing radiation and metabolic gene polymorphisms. J. Toxicol. Environ. Health A 75, 934-946.

Sakly, A., Ayed, Y., Chaari, N., Akrout, M., Bacha, H., Cheikh, H.B., 2012b. Assessment of chromosomal aberrations and micronuclei in peripheral lymphocytes from Tunisian hospital workers exposed to ionizing radiation. Genet. Test. Mol. Biomarkers (Epub ahead of print).

Sari-Minodier, I., Orsière, T., Auquier, P., Martin, F., Botta, A., 2007. Cytogenetic monitoring by use of the micronucleuous assay among hospital workers exposed to low doses of ionizing radiation. Mutat. Res. 629, 111-121.

Shadley, J.D., Wolff, S., 1987. Very low doses of X-rays can cause human lymphocytes to become less susceptible to ionizing radiation. Mutagenesis 2 (2), 95-96.

Sonmez, S., Ikbal, M., Yildirim, M., Gepdiremen, A., Oztas, S., 1997. Sister chromatid exchange analysis in patients exposed to low doses of iodine-131 for thyroid scintigraphy. Mutat. Res. 393, 259-262.

Spitz, D.R., Azzam, E.I., Li, J.J., Gius, D., 2004. Metabolic oxidation/reduction reactions and cellular responses to ionising radiation: a unifying concept in stress response biology. Cancer Metastasis Rev. 23, 311-322.

Stephan, G., Pressl, S., 1999. Chromosomal aberrations in peripheral lymphocytes from healthy subjects as detected in first cell division. Mutat. Res. 446, 231-237.

Tug, E., Kayhan, G., Kan, D., Guntekin, S., Ergun, M.A., 2013. The evaluation of long-term effects of ionizing radiation through measurement of current sister chromatid exchange (SCE) rates in radiology technologists, compared with previous SCE values. Mutat. Res./Genet. Toxicol. Environ. Mutag. 757 (1), 28-30.

United Nations Scientific Committee on the Effects of Atonic Radiationi (UNSCEAR), 2008. Sources and effects of ionizing radiation, vol. I. United Nations, New York.

Vijayalaxmi, Leal, B.Z., Deahl, T.S., Meltz, M.L., 1995. Variability in adaptive response to low dose radiation in human blood lymphocytes: consistent results from chromosome aberrations and micronuclei. Mutat. Res. 348, 45-50. 
Wang, L.E., Bondy, M.L., de Andrade, M., Strom, S.S., Wang, X., Sigurdson, A., Spitz, M.R., Wei, Q., 2000. Gender difference in smoking effect on chromosome sensitivity to gamma radiation in a healthy population. Radiat. Res. 154, 20-27.

Zakeri, F., Hirobe, T., 2010. A cytogenetic approach of the effects of low levels of ionizing radiations on occupationally exposed individuals. Eur. J. Radiol. 73, 191-195.

Zakeri, F., Assaei, R.G., 2004. Cytogenetic monitoring of personnel working in angiocardiography laboratories in Iran hospitals. Mutat. Res. - Genet. Toxicol. Environ. Mutag. 562 (1-2), 1-98.

Zhang, W.Y., Gotoh, T., Oyadomaria, S., Mori, M., 2000. Coinduction of inducible nitric oxide synthase and arginine recycling enzymes in cytokine-stimulated PC12 cells and high output production of nitric oxide. Mol. Brain Res. 83, 1-8.

\section{TABLES}

\section{Table 1 - General characteristics of the exposed and}

\section{control subjects.}

\begin{tabular}{|c|c|c|}
\hline Characteristics & Technicians & Controls \\
\hline Sample size $(n)$ & 21 & 21 \\
\hline \multicolumn{3}{|l|}{ Sex } \\
\hline Males & 13 & 13 \\
\hline Females & 8 & 8 \\
\hline \multicolumn{3}{|l|}{ Age (years) } \\
\hline Mean \pm S.D. & $35.429 \pm 10.073^{\mathrm{a}}$ & $39.905 \pm 7.778^{a}$ \\
\hline Range & $25-57$ & $22-58$ \\
\hline Males & $35.077 \pm 10.696^{\mathrm{b}}$ & $42.846 \pm 6.555^{c}$ \\
\hline Females & $36.000 \pm 9.651^{b}$ & $35.125 \pm 7.549^{c}$ \\
\hline \multicolumn{3}{|c|}{ Years of employment } \\
\hline Mean \pm S.D. & $9.714 \pm 8.730^{d}$ & $10.571 \pm 4.130^{d}$ \\
\hline Range & $1-29$ & $1-19$ \\
\hline Males & $9.692 \pm 8.635^{e}$ & $11.230 \pm 3.320^{f}$ \\
\hline Females & $9.750 \pm 9.483^{e}$ & $9.500 \pm 5.264^{\mathrm{f}}$ \\
\hline \multicolumn{3}{|c|}{ S.D. = standard deviation. } \\
\hline \multicolumn{3}{|c|}{$\mathrm{P}=0.140$} \\
\hline \multicolumn{3}{|c|}{ b $P=0.779$} \\
\hline \multicolumn{3}{|l|}{$\mathrm{P}=0.291$} \\
\hline \multicolumn{3}{|l|}{ d $P=0.445$} \\
\hline \multicolumn{3}{|l|}{ e $P=0.528$} \\
\hline $\mathrm{f} P=0.573$ & & \\
\hline
\end{tabular}




\begin{tabular}{|c|c|c|c|c|c|c|c|c|}
\hline Groups & $\mathrm{N}$ & NSM & SCES & $\mathrm{SCEs} / \mathrm{NSM} \pm \mathrm{S} . \mathrm{E}$ & $\mathrm{M}_{1}$ & $\mathrm{M}_{2}$ & $\mathrm{M}_{3}$ & $\mathrm{RI} \pm \mathrm{S} . \mathrm{E}$. \\
\hline Technicians & 21 & 1050 & 7005 & $6.67 \pm 0.29^{a}$ & 1004 & 846 & 250 & $1.64 \pm 0.05^{b}$ \\
\hline Males & 13 & 650 & 4386 & $6.75 \pm 0.42^{c}$ & 626 & 546 & 128 & $1.62 \pm 0.06^{d}$ \\
\hline Females & 8 & 400 & 2619 & $6.55 \pm 0.36^{c}$ & 378 & 300 & 122 & $1.68 \pm 0.064^{d}$ \\
\hline Controls & 21 & 1050 & 4710 & $4.49 \pm 0.39^{a}$ & 746 & 822 & 534 & $1.90 \pm 0.04^{b}$ \\
\hline Males & 13 & 650 & 3270 & $5.03 \pm 0.44^{e}$ & 476 & 518 & 308 & $1.87 \pm 0.04^{f}$ \\
\hline Females & 8 & 400 & 1440 & $3.60 \pm 0.66^{e}$ & 270 & 304 & 226 & $1.95 \pm 0.083$ \\
\hline \multicolumn{9}{|c|}{$\begin{array}{l}N=\text { number of analyzed subjects; } N S M=\text { number of scored metaphases; SCEs = sister chromatid exchanges; metaphases; RI (replication } \\
\text { index) }=\left(M_{1}+2 M_{2}+3 M_{3}\right) / N \text {, where } M_{1}, M_{2} \text { and } M_{3} \text { represent the number of cells undergoing first second and third mitosis and } N \text { is the total } \\
\text { number of metaphase scored; S.E. = standard error. } \\
\text { a } P=0.003 \text {. } \\
\text { b } P=0.001 . \\
\text { ' } P=0.674 . \\
\text { d } P=0.327 . \\
\text { e } P=0.401 . \\
\text { f } P=0.484 .\end{array}$} \\
\hline
\end{tabular}

\begin{tabular}{|c|c|c|c|c|c|c|c|}
\hline Technicians & 21 & 1050 & 7005 & $6.67 \pm 0.29$ & 941 & $109^{d}$ & $5.19 \pm 2.86$ \\
\hline HFIs & $11(52.38)^{a}$ & 550 & 4190 & $7.62 \pm 0.33^{c}$ & 467 & 83 & $7.55 \pm 1.63$ \\
\hline Controls & 21 & 1050 & 4710 & $4.49 \pm 0.39$ & 1005 & $45^{\mathrm{d}}$ & $2.14 \pm 2.15$ \\
\hline Non-HFIs & $18(85.71)$ & 900 & 3638 & $4.04 \pm 1.53^{b}$ & 873 & 26 & $1.44 \pm 1.34$ \\
\hline \multicolumn{8}{|c|}{$\begin{array}{l}\text { HFCs }=\text { high frequency cells; HFIs = high frequency individuals. } \\
\text { a } P=0.010 . \\
\text { b } P=0.013 . \\
\text { c } P=0.109 \\
\text { d } P<0.001\end{array}$} \\
\hline
\end{tabular}

\begin{tabular}{|c|c|c|c|c|c|c|c|c|c|c|c|}
\hline Groups & \multicolumn{9}{|c|}{ CAs } & $\begin{array}{l}\text { CAs/NSM \% } \\
\text { Mean } \pm \text { S.E. }\end{array}$ & $\begin{array}{l}\text { CAB/NSM } \% \\
\text { Mean } \pm \text { S.E. }\end{array}$ \\
\hline Technicians & 21 & 4200 & 50 & 22 & 2 & 18 & 1 & 93 & 87 & $2.21 \pm 0.20^{a}$ & $2.07 \pm 0.17^{b}$ \\
\hline Males & 13 & 2600 & 37 & 14 & 2 & 10 & 0 & 63 & 58 & $2.42 \pm 0.29$ & $2.23 \pm 0.24^{d}$ \\
\hline Controls & 21 & 4200 & 32 & 5 & 4 & 10 & 0 & 51 & 49 & $1.21 \pm 0.24$ & $1.17 \pm 0.17^{\mathrm{b}}$ \\
\hline Males & 13 & 2600 & 14 & 3 & 3 & 7 & 0 & 27 & 26 & $1.04 \pm 0.29^{e}$ & $1.00 \pm 0.24^{f}$ \\
\hline Females & 8 & 1600 & 18 & 2 & 1 & 3 & 0 & 24 & 23 & $1.50 \pm 0.40^{e}$ & $1.44 \pm 0.33^{f}$ \\
\hline
\end{tabular}

$\mathrm{N}=$ number of analyzed subjects; NSM = number of scored metaphases; CAs: chromosome aberrations; $\mathrm{B}^{\prime}$ : chromatid breaks; $\mathrm{B}^{\prime \prime}$ : chromosome breaks; Dic: Dicentric chromosome; AF = acentric fragments; TR=Tri-or Tetra-radials; $\mathrm{CAB}=$ cells with aberrations. S.E. $=$ standard error.

a $\mathrm{P}=0.006$.

b $\mathrm{P}=0.004$

c $\mathrm{P}=0.235$.

d $\mathrm{P}=0.136$.

e $P=0.832$.

${ }^{f} \mathrm{P}=0.670$.

Table 5 - Multiple regression analysis of confounding factors on CAs, CAB and SCEs frequencies in peripheral

lymphocytes of the study groups.

\begin{tabular}{|c|c|c|c|c|c|c|c|c|c|}
\hline \multirow[t]{2}{*}{$\mathrm{CF}$} & \multicolumn{3}{|c|}{ CAs frequency } & \multicolumn{3}{|c|}{ CAB frequency } & \multicolumn{3}{|c|}{ SCEs frequency } \\
\hline & $\beta$-co & P-value & $\begin{array}{c}95 \% \text { CI } \\
\text { Lower-upper }\end{array}$ & $\beta$-со & P-value & $\begin{array}{c}95 \% \text { CI } \\
\text { Lower-upper }\end{array}$ & $\beta$-co & P-value & $\begin{array}{c}95 \% \text { CI } \\
\text { Lower-upper }\end{array}$ \\
\hline \multicolumn{10}{|c|}{ Technicians } \\
\hline Age & 0.033 & 0.887 & $-2.474-4.610$ & -0.024 & 0.919 & $-2.180-3.834$ & -0.009 & 0.993 & $-8.003-7.935$ \\
\hline Y.E. & -0.023 & 0.920 & $-2.456-4.539$ & -0.079 & 0.732 & $-2.222-3.764$ & 0.256 & 0.801 & $-8.072-10.316$ \\
\hline \multicolumn{10}{|c|}{ Controls } \\
\hline Age & -0.245 & 0.285 & $-2.422-4.831$ & -0.194 & 0.399 & $-2.329-4.177$ & 1.060 & 0.017 & $2.478-22.037$ \\
\hline Y.E. & -0.118 & 0.611 & $-2.566-5.492$ & -0.101 & 0.633 & $-2.358-4.466$ & -0.453 & 0.275 & $-28.278-8.553$ \\
\hline
\end{tabular}

